\title{
Impact of Grid Connected Photovoltaic System in the Power Quality of a Distribution Network
}

\author{
Pedro González, Enrique Romero-Cadaval, Eva González, \\ and Miguel A. Guerrero \\ Power Electrical and Electronic Systems (PE\&ES), \\ School of Industrial Engineering (University of Extremadura) \\ http: //peandes. unex.es
}

\begin{abstract}
Photovoltaic (PV) systems are increasingly present in the electrical distribution systems due to the governments incentives and low production costs of a developed PV technology. This paper summarizes the measurements on power quality $(\mathrm{PQ})$ parameters carried out in a radial distribution network in two periods of time, before and after connecting a PV plant to the grid, and also shows the same parameters measured in the point of common coupling (PCC) of the grid and PV plant in order to discuss about how the impedance of the grid and ratio between injected power and power demanded by the load may influence changes on the PQ of the distribution system. Some measured values are compared with the limits set in the international standards. This paper assesses the impact of PV generation on the distribution system and important issues such as reverse power flow and harmonic distortion are analyzed.
\end{abstract}

Keywords: PV grid connected systems, power quality, distributed generation.

\section{Introduction}

The increasing number of photovoltaic systems in Spain is a fact in recent years due to the commitment made by the government with the European Union in terms of increasing the percentage of renewable energy in the generation mix. Optimal conditions for the development and implementation of this technology has meant that in $20086090 \mathrm{MW}$ of PV power was installed in the world. Spain was the leader with approximately $43 \%$ according to [1]. Until recently, the performance of photovoltaic plants and technological improvements to reach an increase in the productivity, have been the focus of the research [2-5]. In short time, the advance of the solar technology is evident, and at this point it is necessary to deepen the performance of the facilities, but also to know the impact of those plants on the grid, even more because of actual PV high penetration levels in the distribution networks. The potential problems associated with high PV penetration levels are summarized in [6] and could be a disadvantaged for the development of this renewable energy.

For unmanaged generation plants in Spain [7], the generation capacity shall not exceed one twentieth of the power network short circuit at the PCC in order to mitigate the possible effects of the PV plant on the distribution network. To obtain an accuracy value of the short circuit power in distribution networks before the installation of a PV plant, is not easy. The impedance of the grid, which is directly related to the short circuit power, changes with frequency and its estimation could be complicated with the presence of more than one generation source on the network. 
PV system location on the distribution system could influence the PQ of the grid at the PCC [8] and also the difference between the load conditions and PV production could affects the voltage fluctuation of the grid due to the reverse power flow [9], [10]. Taking into account all these factors, this paper presents measurements performed on a distribution network in two situations, before and after the PV system connection to the grid with the aim of evaluate the impact of PV systems, not only in the substation, but also in the PCC.

\section{Contribution to Sustainability}

Grid interconnection of PV generation system has the advantage of more effective utilization of generated power with a more flexible and accommodated consumption. PV systems are a solution for the dependence and depletion of conventional energy sources and environmental problems. PV generation is increasingly widespread in the distribution network and quality problems have been detected that may affect the operation of the network. This paper presents experimental measures on a distribution grid, with and without connection of PV plant, to have a better understanding of the potential quality problems that this technology may introduce on the grid and to be able to solve them. Improving PV plants operation could increase the penetration level of PV plants in the distribution system.

\section{Description of PV Grid Connected System}

The size and the peak power of the PV system, the rated power and the short circuit power of the grid are important parameters to evaluate the PV influence on the grid, all of them related to the PV power penetration level. According to [11], most of the problems observed in an experimental analysis performed, occur in rural networks due to its high impedance. Taking this into account in the selection process of the line, measured data of different rural distribution lines was analyzed from year 2005 to year 2007, to choose one of them with a low load and not many changes in their annual load profiles. The line chosen has similar load profiles in different years with a low demand of power Fig. 1, and only reaches high values of load from April to August when rural customers develop their maximum activity. The other requirement to select the appropriate line was to have a recent PV generation connected to have measured data of both situations (with and without PV generation). The line studied is a rural distribution grid of $20 \mathrm{kV}$ in the southwest of Spain with an approximated installed power of $5 \mathrm{MW}$ that supplies to 115 customers, including a small town and also many dispersed irrigated farms. The line is connected to a 20 MVA transformer in a substation with two levels of voltages $66 \mathrm{kV} / 20 \mathrm{kV}$.

The PV plant is located $4 \mathrm{~km}$ from the substation and started operating in 2008. The PV system has $5 \mathrm{~kW}-2 \Phi, 20 \mathrm{~kW}-3 \Phi$ and $100 \mathrm{~kW}-3 \Phi$ inverters, all them equipped with AC galvanic isolation transformer and the usual protections of the majority of inverters used in PV installation such as: reverse polarity, AC over/under voltage, DC over voltage, AC and DC overcurrent, over temperature and antiislanding. PV park is made up of $6633 \mathrm{PV}$ modules with $150 \mathrm{~W}$ of nominal power arranged in 390 parallel strings, with 17 modules in each. Strings are connected to inverters with different power. There are groups of $15 \mathrm{~kW}, 20 \mathrm{~kW}$ and $100 \mathrm{~kW}$ making a total of $995 \mathrm{~kW}$ of 
installed power. All inverters are tied to the grid via four $0.4 \mathrm{kV} / 20 \mathrm{kV}$ transformers, two of them of $630 \mathrm{kVA}$ of power and another two of $400 \mathrm{kVA}$, which raise the voltage from $400 \mathrm{~V}$ to $20 \mathrm{kV}$ before PV plant being connected to the grid.

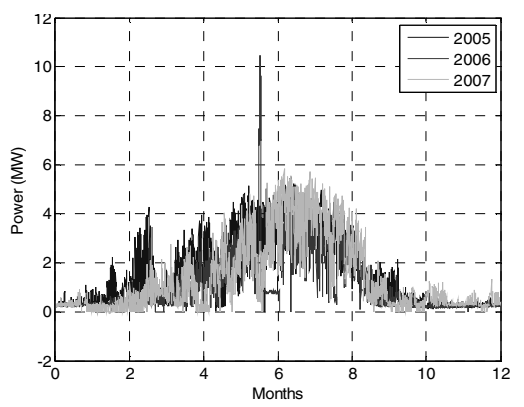

Fig. 1. Load profile of the grid from 2005 to 2007

\section{Measure Methodology}

Accomplishing with the objectives of this work, a PQ analyser (Topas 1000), was installed in two points of the grid: firstly at the substation, to obtain data measured in two periods of time (with and without PV generation connected to the network) and performance a comparative analysis of two monitoring periods and secondly at the PCC to evaluate the quality of the power injected into the network by the PV system.

Several electrical quantities and parameters as active and reactive power, power factor, total current harmonic distortion (THDI) and voltage harmonic distortion (THDU), individual current and voltage harmonics have been observed. All the monitoring periods were carried out for 24 hours in different days, grid without PV system was monitored at the substation on February 26, 2007; grid with PV system was monitored at the substation on March 31, 2009 and finally the output of PV system was monitored at the PCC on March 3, 2010.

PQ analyser Topas 1000 was connected at the low-voltage side of currents $(300 \mathrm{~A} / 60 \mathrm{~A})$ and voltages $(22 \mathrm{kV} / 110 \mathrm{~V})$ transformers at the substation and in the same way, after the general switch of PV system to curry out the measurement at the PCC (Fig. 2). PQ analyser has 8 channels to measure currents and voltages; it is connected to four wire system with neutral-voltage/current and neutral common point connected to ground. Topas equipment recorded data with measurement interval of $10 \mathrm{~ms}$ for rms values, for this work, average intervals of 1 minute have been selected.

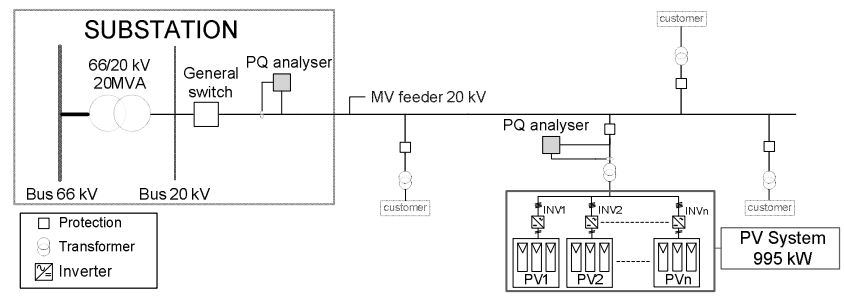

Fig. 2. Schematic block circuit diagram of the grid and PV system 


\section{Results}

In the following subsections the most representative measured parameters are presented and compared with the limits set in the corresponding standards. [11] is considerated to evaluate all values measured at the substation in 2007 (without PV plant) and 2009 (with PV grid connected plant), It refers to [12] for analyzing the values of the parameters measured at the PCC in 2010.

\subsection{Power Quality on the Grid Measured at the Substation}

It should be emphasized several issues to analyze the recorded data: the difference between the load and PV production significantly influences all parameters measured, that is; when the power produced by PV system is comparable with the power supplied by the main source of the grid, the behavior of the photovoltaic plant is most noticeable in the network, even more because PV system studied is near the substation and there is little impedance between them.

Active Power. The load profile of the grid in the last years was very flat and low, the value of $5 \mathrm{MW}$ installed never is reached, even in the months of more activity. The demand of power monitored in both periods (2007 and 2009) was below 2 MW and on the other hand PV plant produced $995 \mathrm{~kW}$ in optimal conditions, so the reverse power flow could be. In Fig. 3 a), b); active power profile in 24 hours is shown, it is observed in b) how PV plant production affects the flow of energy for several hours at the substation.

Reactive Power. There was an increase in the reactive power consumption in the network with PV system Fig. 3 d) compared with the first period Fig. 3 c). The PV inverters are subject to the action of control systems aimed at providing zero reactive power at fundamental frequency, but several experiences has shown that the filters of inverters are not disconnected consuming reactive power, even when PV plant is not operating. This fact does not justify such a reactive power consumption, which may be due to increased loads on the grid in recent years.

Power Factor. As can be observed in Fig. 3 e), the power factor values are always above 0.85 and only fell below this number at night when the load profile is low, however in Fig. $3 \mathrm{f}$ ), power factor decreases to unacceptable levels during PV system operation. When PV system works with high power values close to rated ones, most active power demanded by the customers is supplied by the PV plant, reducing the demand of active power from the grid, but reactive power demand is the same, so it causes a low power factor measured at the substation.

Current and Voltage Harmonic Distortion. Voltage distortion is due to the currents demanded by nonlinear loads, these currents flowing through the impedances of the grid affecting the voltage nodes. The standard [11] limits THDU to 8\% and also the individual voltage harmonics. Fig. 3 i), j) and Fig. 4 c), d) shows the voltage harmonic distortion does not exceed the limits set by the standard, so in terms of voltage distortion, the effect of PV system operation is negligible.

Current distortion is due to the current waveforms demanded by nonlinear loads and also the current injected by PV inverters into the grid. THDI Fig. $3 \mathrm{~g}$ ), and also 
high individual currents harmonics observed in Fig. 4 a) are due to a low value of fundamental component of current, however, it can be noted the presence of 40th harmonic due to switching signals of PV inverters at the substation Fig. 4 b), and extremely high values of THDI occur when PV system reach rated power and the reverse power flow is produced at the substation Fig. $3 \mathrm{~h}$ ).

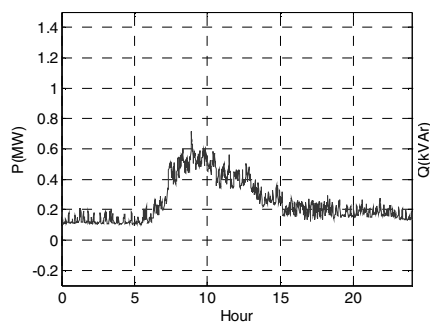

a)

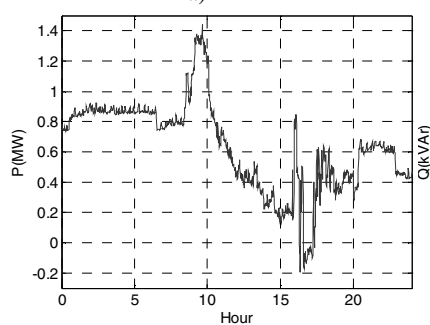

b)

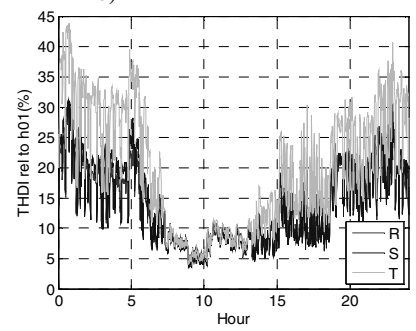

g)

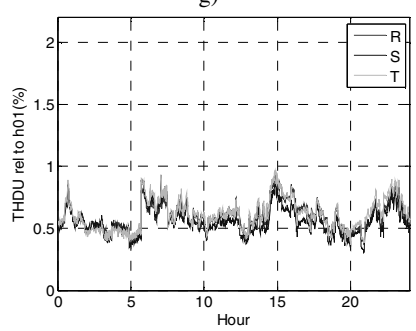

i)

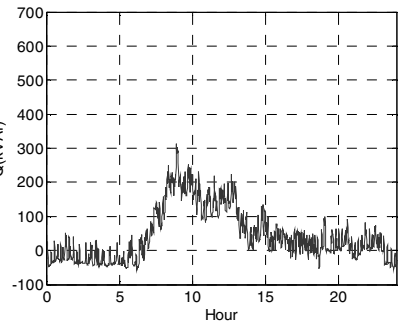

c)

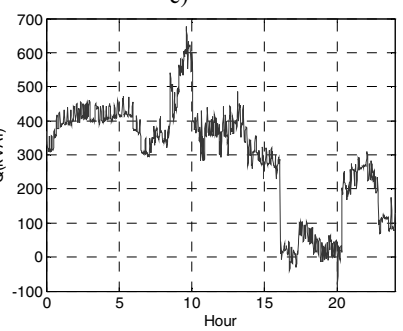

d)

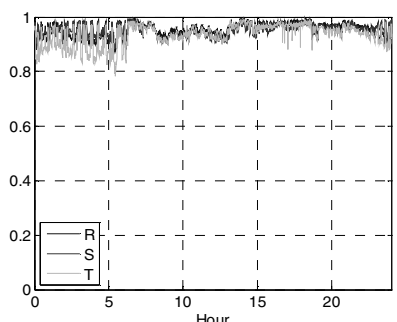

e)

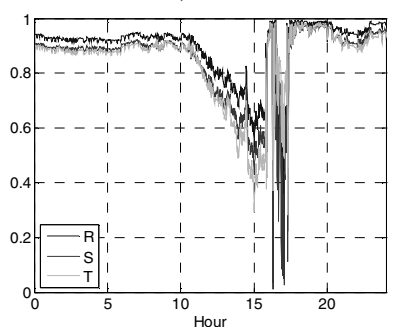

f)

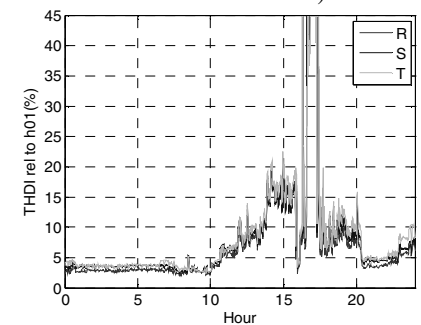

h)

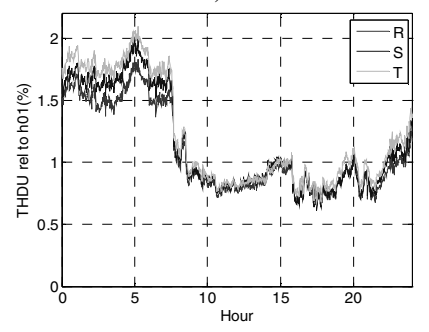

j)

Fig. 3. Measures at the substation in 24 hours. Active power: a) without PV, b) with PV; reactive power: c) without $\mathrm{PV}, \mathrm{d}$ ) with PV; power factor: e) without PV, f) with PV; THDI: g) without PV, h) with PV; THDU: i) without PV, j) with PV. 


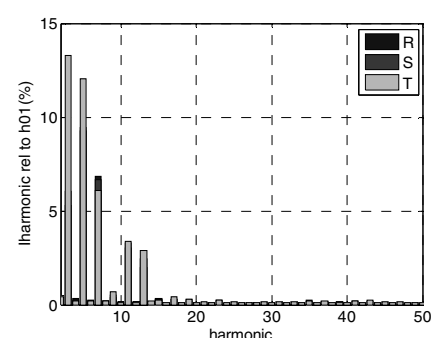

a)

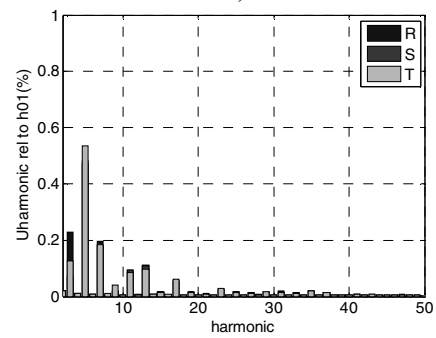

c)

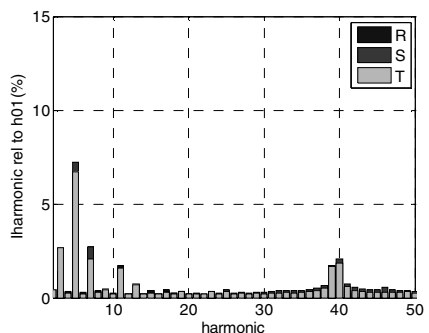

b)

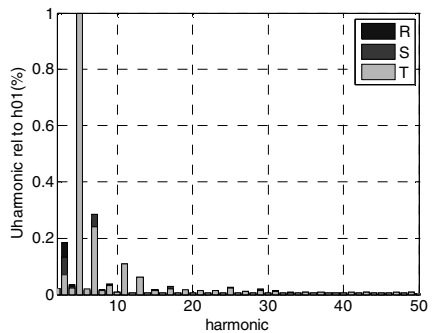

d)

Fig. 4. Individual currents harmonics in 24 hours, a) without $P V, b$ ) with $P V$ and individual voltages harmonics in 24 hours, c) without PV, c) with PV

\subsection{Power Quality on the Grid Measured at the PCC}

PV power quality injected into the grid is evaluated at this point, the rated power of PV system compared with the short circuit power al the PCC, is important to analyze the values of the different measured parameters and their influence on the grid.

In Fig. 5 a), PV plant active power profile is shown. The power fluctuations in active power profile are typical of a cloudy day and only the rated power is reached one time at 15 hour. Also in Fig. 5 b), is possible to see a demand of reactive power by the loads of the grid. It is observed fluctuations in reactive power before and after PV plant operation but there is not reactive power consume at night.

According to [12], the PV system should operate with a power factor above 0.85 when output exceeds $10 \%$ of the nominal power. As can be seen in Fig. 5 a), active power is always above $10 \%$ of the rated power of the plant $(995 \mathrm{~kW})$, however many times the power factor is below 0,8 Fig. 5 c). These values can only be justified if PV system provides reactive power compensation.

The voltage profile is shown in Fig. 5 d), it is observed that the values of voltage are within the normal voltage operating range set in [12]. Usually voltage variations are due to currents generated by the inverters that produce dangerous overvoltage when the PV power is similar to the power demanded by loads. The IEEE Standard 519-1996 states a maximum of 3\% for the individual harmonic distortion and a maximum of $5 \%$ for THDU. None of those limits are reached at the PCC Fig. $5 \mathrm{f}$ ), h).

The current harmonic are related to the inverter operation, inverter manufacturers claim that their inverters provide a THDI $<3 \%$ when operating at $30 \%$ of rated power and this situation is very common. The same occurs with the standard [12], it recommend the inverter to supply a current with less than $5 \%$ TDHI when at the 
nominal power. In Fig. 5 e), it can be seen that THDI measured is around this value. For individual current harmonic [12] limits in $4 \%$ for $3^{\text {th }}-9^{\text {th }}$ harmonics, $2 \%$ for $11^{\text {th }}-15^{\text {th }}, 1,5 \%$ for $17^{\text {th }}-21^{\text {th }}$ and $0,6 \%$ for $23^{\text {th }}-33^{\text {th }}$. In Fig. 5 g), as can been observed all the limits are exceeded due to periods when the fundamental component of current is close to zero. It can be noted again at the PCC, the $40^{\text {th }}$ harmonic due to switching signal of inverters, which is not set in the standards.

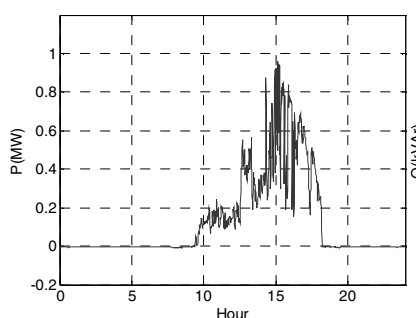

a)

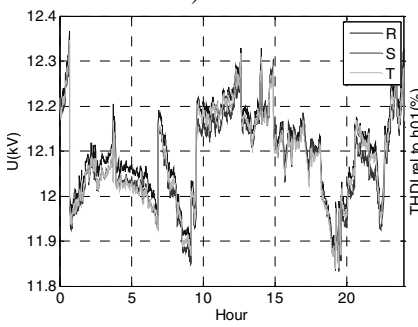

d)

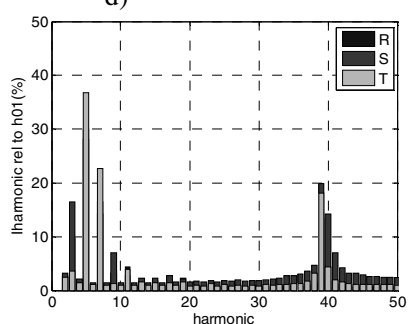

g)

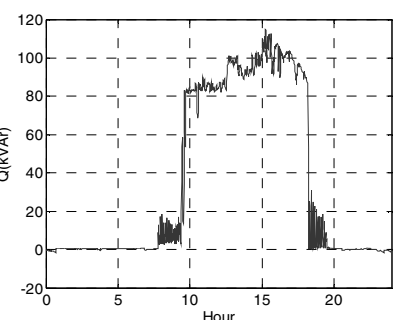

b)

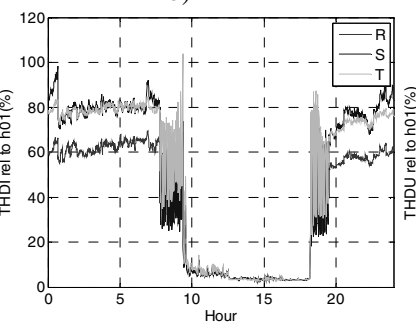

e)

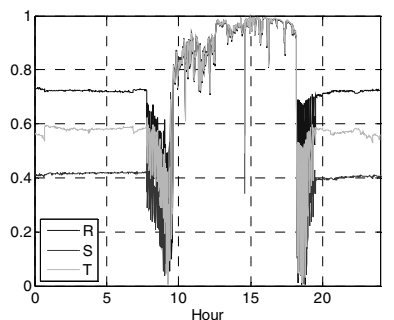

c)

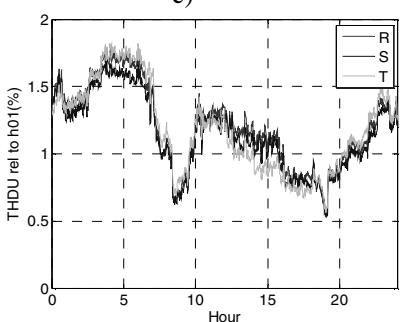

f)

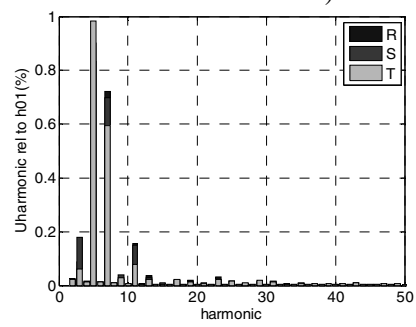

h)

Fig. 5. Measures at the PCC in 24 hours: a) active power, b) reactive power, c) power factor, d) voltage variations, e) THDI, f) THDU, g) individual current harmonics, h) individual voltages harmonics

\section{Conclusions}

The measures carried out on the grid, have shown the influence of PV system in the power quality of the distribution network, the insertion of PV plant causes changes in measured quality parameters and operational particularities that do not seriously affect to the operation of the grid due to the power limit of twentieth of the power network short circuit for generation plants set in [7]. In a near future, if this power ratio increases, it could be necessary to find out solutions to mitigate the impact of these 
quality particularities on the grid. Distribution network have been designed to operate in radial configuration with only consumption nodes, but actually it is common to find distribution networks with several generation points that could cause reverse power flow and voltage fluctuations in different parts of the grid. For this reason to review the management and protection devices of the distribution networks will be important issues. Storage devices and advanced inverters with internal controls that allow the adjustment of injected power as required by the grid, could be optimal options to taking into account.

\section{Acknowledgements}

This work was supported by electricity company Endesa under research contract with the University of Extremadura.

\section{References}

1. European Photovoltaic Industry Association publications: Global Market Outlook for Photovoltaics Until 2014 (May 2010), http: / / www . epia. org

2. Hun So, J., Seok Jung, Y., Jong Yu, G., Yeop Choi, J., Ho Choi, J.: Performance results and analysis of $3 \mathrm{~kW}$ grid-connected PV systems. Renewable Energy 32, 1858-1872 (2007)

3. Sidrach de Cardona, M., Mora López, L.1.: Performance analysis of a grid-connected photovoltaic system. Energy 24, 93-102 (1999)

4. Deb Mondol, J., Yohanis, Y., Smyth, M., Norton, B.: Long term performance analysis of a grid connected photovoltaic system in Northern Ireland. Energy Conversion and Management 47, 2925-2947 (2006)

5. Kymakis, E., Kalykakis, S., Papazoglou, T.M.: Performance analysis of a grid connected photovoltaic park on the island of Crete. Energy Conversion and Management 50, 433-438 (2009)

6. Eltawil, M.A., Zhao, Z.: Grid -connected photovoltaic power systems: Technical and potential problems-A review. Renewable and Sustainable Energy Reviews 14, 112-129 (2010)

7. Royal Decree 661/2007 on the Official State Gazette (BOE), 126, 22846-22886 (2007) Regulation of the activity of production of electrical energy in special regime

8. Srisaen, N., Sangswang, A.: Effects of PV grid-connected system location on a distribution system. In: IEEE Asia Pacific Conference on Circuits and Systems, Singapore, pp. 852-855 (2006)

9. Negrão Macêdo, W., Zilles, R.: Influence of the power contribution of a grid-connected photovoltaic system and its operational particularities. Energy for Sustainable Development 13, 202-211 (2009)

10. Canova, A., Giaccone, L., Spertino, F., Tartaglia, M.: Electrical impact of photovoltaic plant in distributed network. IEEE Transactions on Industry Applications 45(1), 341-347 (2009)

11. Voltage characteristics of electricity supplied by public distribution system, CEI EN 50160 (2000)

12. IEEE Std. 929-2000, IEEE Recommended practice for utility Interface of photovoltaic (PV) systems sponsored by IEEE Standards Coordinating Committee 21 on Photovoltaics, IEEE Std. 929-2000, IEEE, New York, NY (April 2000) 